\title{
Особенности интервенционных вмешательств при хронических коронарных окклюзиях у больных с ишемической болезнью сердца после аортокоронарного шунтирования. Состояние вопроса и собственный опыт
}

\author{
Фуркало С. Н. \\ ДУ «Национальный институт хирургии и трансплантологии им. А. А. Шалимова НАМН Украины», г. Киев, Украина
}

\begin{abstract}
Резюме. В течение 10 лет после аортокоронарного шунтирования (АКШ) $60 \%$ венозных шунтов и $90 \%$ трансплантатов внутренней грудной артерии (ВГА) остаются функционирующими. Частота прогрессирования проксимальных стенозов шунтированных артерий до полных окклюзий составляет $22 \%$ при использовании ВГА как артериального анастомоза и 48 \% в среднем после применения аутовенозных трансплантатов. В соответствии с литературными данными, при многофакторном анализе больные, перенесшие АКШ и подвергающиеся последующей коронарной ангиопластике, имеют более высокий риск вмешательства в отношении смертности и послеоперационных осложнений. Если реканализация артерии прошла успешно, смертность достигала $2,6 \%$, в случае частичного успеха $-5,2 \%$, а в случае неудачи летальность составила $8,2 \%$.

При вмешательстве у больных после АКШ предпочтительной является реканализация окклюзий нативных коронарных артерий, нежели аорто-коронарных трансплантатов.

В настоящей работе представлен анализ возможных интервенционных подходов к реканализации коронарного русла у больных после АКШ, обсужден собственный опыт и практические наработки. Реканализации хронических окклюзий коронарных артерий в различные сроки после АКШ с общей технической эффективностью 75 \% подверглись 52 больных.
\end{abstract}

Ключевые слова: атеросклероз коронарных артерий, аортокоронарное шунтирование, хронические коронарные окклюзии, стентирование коронарных артерий.

Вступление. Необходимость в повторных вмешательствах у больных с ишемической болезнью сердца (ИБС)

после перенесенного ранее аортокоронарного шунтирования (АКШ) определяется состоянием коронарных шунтов и прогрессированием атеросклероза нативного коронарного русла. В течение 10 лет после АКШ только $60 \%$ венозных шунтов и $90 \%$ маммарных анастомозов остаются функционирующими [2, 6]. Результаты послеоперационной коронарографии указывают на ускорение процессов в шунтированных коронарных артериях, которые приводят к прогрессированию существующих поражений и возникновению полных окклюзий.

По мере совершенствования интервенционной техники повторные АКШ при рецидиве клинической картины снизились до 3 \% всех повторных вмешательств, и в большинстве случаев у этих пациентов выполняются интервенционные вмешательства.

Как правило, атеросклеротический процесс в коронарных артериях после перенесенного АКШ характеризуется более выраженными проявлениями. Несмотря на то что точный механизм изменений не совсем ясен, в ряде клинических исследований было отмечено, что атеросклеротический процесс развивается бо- лее активно в шунтированных артериях, нежели в нешунтированных $[1,4,7]$.

Кроме того, прогрессирование от стенозирования до полных коронарных окклюзий является обычным состоянием в шунтированных коронарных артериях [8]. Интервенционные вмешательства тут бывают более длительными, технически требовательными, часто вследствие твердой проксимальной и дистальной чашек окклюзии, сформированных в зоне высокого давления из-за функционирования аортокоронарных шунтов $[3,5,9]$.

Перкутанные вмешательства на хронически окклюзированных нативных коронарных артериях (XКО) достаточно эффективны, чаще осуществляются с применением ретроградного доступа как через функционирующие коллатерали, так и через функционирующие либо стенозированные аортокоронарные шунты.

Интервенционные вмешательства на венозных шунтах также проводятся с высокой эффективностью, но с несколько большим числом осложнений. Стенозирование внутренней грудной артерии, использованной как артериальный шунт происходит значительно реже, однако стентирование также возможно. 
Большинство эндоваскулярных вмешательств после АКШ проводятся в зоне нативного коронарного русла. Вне зависимости от подхода при выполнении реканализации ХКО результаты вмешательства у больных после АКШ в случае успеха значительно лучше, нежели в случае неудачи [5]. Наличие конкурентной ХКО может негативно влиять на исход при возникновении острого коронарного синдрома, так как под угрозой оказывается больший регион миокарда.

Кальцинированные поражения также ассоциируются со сложностями в реканализации ХКО. Распространенный кальциноз может объяснить более низкий успех реканализации окклюзий у больных после перенесенного АКШ (> 2 лет назад) в сравнении с больными без предшествующего АКШ.

Brilakis E. et al., анализируя данные National Cardiovascular Data Registry, приводят результаты перкутанных вмешательств у 300902 пациентов, ранее перенесших АКШ. Ангиопластика нативных коронарных артерий осуществлена у 62,5 \% пациентов, в остальных случаях выполнялись вмешательства на коронарных шунтах, причем $34,9 \%$ на венозных и в 2,5\% на артериальных анастомозах.

При мультивариантном анализе, интервенционные вмешательства на венозных шунтах имели более высокие показатели госпитальной летальности и периоперационных осложнений. Перкутанные вмешательства ХКО нативных коронарных артерий у пациентов после АКШ осуществлено у 16376 пациентов $(5,4 \%)$ и были успешны у 76,6 \% случаев, однако с повышенной госпитальной смертностью в этой подгруппе $(3,4 \%)$. Смертность составляла $2,6 \%$, если реканализация была успешна, 5,2 - в случае частичного успеха вмешательства и 8,2 \% - в случае неудачи вмешательства [2].

В соответствии с современными данными, у больных без предшествующего АКШ ХКО определяется у $18,4 \%$ пациентов, перенесших плановую коронарографию. Эффективность реканализации ХКО при использовании современного оборудования превышает $85 \%$ [10]. Тогда как у больных, перенесших АКШ, окклюзия как минимум одной коронарной артерии фиксировалась в 50 \% случаев. Реканализация ХКО в этой подгруппе больных сопровождается значительным числом осложнений, а эффективность не превышала $80 \%$. Литературные источники свидетельствуют, что ретроградный подход применяется у больных после АКШ чаще [12, 13].

Цель. Проанализировать возможности и непосредственные результаты интервенционных вмешательств у больных с ИБС после АКШ с рецидивом клинических проявлений.

Материалы и методы. Нами проанализированы интервенционные вмешательства у 154 больных после АКШ, где зафиксирован рецидив клинических про- явлений в отдаленный период наблюдения - от 6 месяцев до 24 лет после оперативного лечения. Для осуществления интервенционных вмешательств в виду полных хронических окклюзий коронарных артерий был отобран 51 больной. Вмешательство считалось целесообразным при наличии жизнеспособного миокарда в зоне перфузии окклюзированной артерии. Возраст больных колебался в пределах 38-75 лет. Большинство пациентов характеризовалось выраженной клинической картиной коронарной недостаточности. Так, более 40 \% больных имели стенокардию III-IV функционального класса, у 33 \% пациентов отмечено нестабильное течение заболевания, что часто определялось недавней окклюзией аутовенозного шунта. Реканализация хронически окклюзированных коронарных шунтов нами не осуществлялась кроме одного случая ввиду долгосрочной неэффективности такого вмешательства. Сократительная способность миокарда левого желудочка была несколько снижена в целом в группе (фракция выброса 46,6 \%) - от 29 до $60 \%$.

Кроме осуществления коронарографии в комплекс исследований входило ультразвуковое исследование, нагрузочное тестирование, а также методики определения жизнеспособности миокарда - магнитнорезонансная томография, сцинтиграфия миокарда с технецием или нагрузочные пробы с добутамином. Миокард в зоне перфузии окклюзированной артерии считался жизнеспособным при отсутствии в анамнезе инфаркта миокарда, Q-волны на электрокардиограмме в соответствующих отведениях, а также отсутствие зон акинезии и дискинезии.

Результаты и обсуждение. В 51 случае интервенционные вмешательства выполнены на окклюзированных коронарных артериях при нефункционирующих шунтах. В 1 случае реканализировался окклюзированный венозный шунт. Наиболее часто реканализация хронической окклюзии выполнена при поражении правой коронарной артерии (ПКА) - 73,7 \%, реже при окклюзии передней межжелудочковой вены (ПМЖВ) левой коронарной артерии (ЛКА) - 15,8 \% и огибающей вены (ОВ) ЛКА - 10,5\%.

В $67,3 \%$ случаев для реканализации окклюзии применен антеградный доступ, в 32,7 \% выполнялся ретроградный доступ (рисунок 1). В настоящее время ретроградный подход может быть классифицирован следующим образом: прямая ретроградная реканализация проводником (retrograde wire crossing), техника «целующихся» проводников (kissing wire crossing), контролируемая антеградно-ретроградная субинтимальная реканализация «CART» и обратная антеградно-ретроградная субинтимальная реканализация, или «reverse CART».

Первичная эффективность вмешательств составила $75 \%$, что несколько ниже, нежели эффективность в группе первичных больных. 


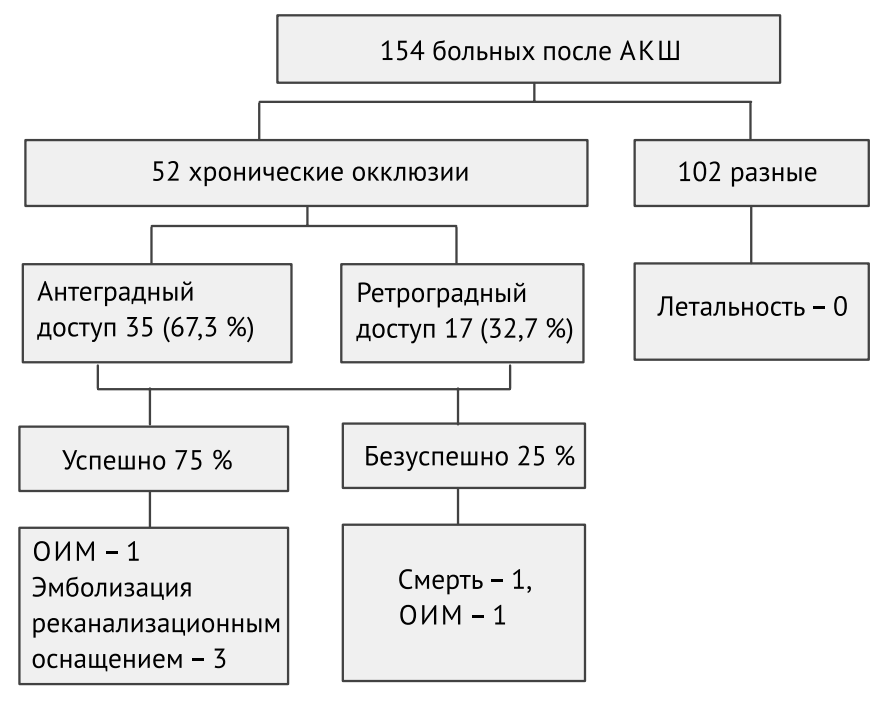

Рисунок 1. Больные после АКШ, где выполнены коронарные интервенционные вмешательства

Примечание. ОИМ - острый инфаркт миокарда.

Повторную попытку реканализации ХКО с эффективностью 54,5\% перенесли 11 пациентов. Третья попытка была эффективна еще у двух больных. Таким образом, вторичная эффективность интервенционных вмешательств составила около $88 \%$, что соответствует показателям реканализации коронарных окклюзий в стандартных случаях в экспертных центрах. Внутрисосудистое ультразвуковое исследование (ВСУЗИ) применено у 3,8 \% пациентов как для оценки размера стентируемой артерии, так и для локализации проводника в истинном просвете артерии. В соответствии с современными представлениями ВСУЗИ особенно эффективно в руках опытных операторов в случае анатомически сложных коронарных окклюзий, где ЈСТО > 3.

Отдельного обсуждения заслуживает случай летального исхода у больного во время попытки реканализации хронической окклюзии ПКА. Вследствие руптуры коллатерали при попытке ретроградного доступа возникла «сухая тампонада», сдавление полостей сердца и кардиогенный шок. В случае возникновения вышеназванного осложнения арсенал возможных вмешательств для стабилизации состояния достаточно ограничен.

Возможности коронарных вмешательств после АКШ с использованием артериальных анастомозов заслуживает отдельного обсуждения. Внутренняя грудная артерия (ВГА) менее склонна к атеросклеротическим изменениям, однако более склонна к спазму. ПМЖВ ЛКА, шунтированная с применением ВГА, остается подверженной атеросклеротическому процессу, невзирая на применение артериального анасто- моза и может вести к дестабилизации клинического течения [11]. Учитывая сложность доступа, спастические реакции, малый диаметр артерии и большую площадь миокарда, кровоснабжаемого шунтом ВГА, использование ВГА для реканализации ХКО ограничены. Тем не менее такие случаи давно обсуждаются в литературе.

Выводы

1. Окклюзия коронарных шунтов или прогрессирование атеросклероза нативного коронарного русла после операциии АКШ характеризуются выраженной клинической картиной коронарной недостаточности.

2. Хронические окклюзии коронарных артерий после АКШ имеют неблагоприятные характеристики для реканализации и более технически требовательны, нежели окклюзии без предшествующего коронарного шунтирования.

3. Ретроградный доступ при реканализации хронических окклюзий после АКШ применяется значительно чаще, а эффективность вмешательства заметно ниже, нежели у первичных пациентов.

4. При интервенционных вмешательствах в случае ХКО у больных после АКШ возможны стадийные интервенционные вмешательства.

5. Повторные попытки реканализации артерии при ранее безуспешной попытке позволяют существенно улучшить результаты и были эффективны в половине случаев.

\section{Список использованных источников References}

1. Alhejily WA, Kong DF, Magnus Ohman E. Retrograde approach to coronary chronic total occlusion via an occluded saphenous bypass graft: a case report. Clin Case Rep. 2013;1(2):54-8. https://doi.org/10.1002/ccr3.23

2. Brilakis ES, Rao SV, Banerjee S, Goldman S, Shunk KA, Holmes DR Jr, et al. Percutaneous coronary intervention in native arteries versus bypass grafts in prior coronary artery bypass grafting patients: a report from the National Cardiovascular Data Registry. JACC Cardiovasc Interv. 2011;4(8):844-50. https://doi.org/10.1016/j. jcin.2011.03.018

3. Brilakis ES, Banerjee S, Lombardi WL. Retrograde recanalization of native coronary artery chronic occlusions via acutely occluded vein grafts. Catheter Cardiovasc Interv. 2010;75(1):109-13. https://doi.org/10.1002/ccd.22196

4. Burke AP, Weber DK, Kolodgie FD, Farb A, Taylor AJ, Virmani R. Pathophysiology of calcium deposition in coronary arteries. Herz. 2001;26(4):239-44.

5. Touma G, Ramsay D, Weaver J. Chronic total occlusions Current techniques and future directions. Int $\mathbf{J}$ Cardiol Heart Vasc. 2015;7:28-39. https://doi.org/10.1016/j. ijcha.2015.02.002

6. Galassi AR, Brilakis ES, Boukhris M, Tomasello SD, Sianos G, Karmpaliotis D, et al. Appropriateness of percutaneous revascularization of coronary chronic total occlusions: An 
overview. Eur Heart J. 2016 Sep;37(35):2692-700. https:// doi.org/10.1093/eurheartj/ehv391

7. Michael TT, Mogabgab O, Alomar M, Kotsia A, Christopoulos G, Rangan BV, et al. Long-term outcomes of successful chronic total occlusion percutaneous coronary interventions using the antegrade and retrograde approach. J Interv Cardiol. 2014;27:465-71. https://doi.org/10.1111/ joic. 12149

8. Sakakura K, Nakano M, Otsuka F, Yahagi K, Kutys R, Ladich E, et al. Comparison of pathology of chronic total occlusion with and without coronary artery bypass graft. Eur Heart J. 2014;35(25):1683-93. https://doi.org/10.1093/ eurheartj/eht422

9. Sekiguchi M, Yamazaki M, Kurabayashi M. Retrograde percutaneous coronary intervention via critically degenerated saphenous vein grafts for chronic total occlusion in native coronary arteries. World Journal of Cardiovascular Diseases. 2013;3(3):261-5. https://doi. org/10.4236/wjcd.2013.33041.

10. Sianos G, Werner GS, Galassi AR, Papafaklis MI, Escaned J, Hildick-Smith D, et al. Recanalisation of chronic total coronary occlusions: 2012 consensus document from the EuroCTO club. EuroIntervention. 2012;8(1):139-45. https://doi.org/10.4244/EIJV8I1A21

11. Torii S, Masuda N, Ikari Y. Retrograde approach via left internal mammary artery using a $5 \mathrm{Fr}$ guiding catheter. Cardiovasc Interv Ther. 2016 Apr;31(2):156-60. https:// doi.org/10.1007/s12928-015-0333-5

12. Yang C-F, Chen YM, Chen M-L, Wang, J-H. Successful Revascularization of Chronic Total Occlusion in Native Coronary Arteries through an Occluded Saphenous Bypass Vein Graft: A Retrograde Alternative Approach. Acta Cardiol Sin. 2014;30(5):485-9.

13. Azzalini L, Ojeda S, Karatasakis A, Maeremans J, Tanabe M, La Manna A, et al. Long-Term Outcomes of Percutaneous Coronary Intervention for Chronic Total Occlusion in Patients Who Have Undergone Coronary Artery Bypass Grafting vs Those Who Have Not. Can J Cardiol. 2018 Mar;34(3):310-8. https://doi.org/10.1016/j. cjca.2017.12.016

\title{
Peculiarities of Interventions in Chronic Coronary Occlusions in Patients with CHD after CABG. State of the Art and Actual Experience
}

\author{
Furkalo S. N.
}

\section{A. A. Shalimov National Institute of Surgery and Transplantology, Kyiv, Ukraine}

Abstract. Within 10 years after coronary artery bypass grafting (CABG) only $60 \%$ of vein grafts and $90 \%$ of internal mammary artery (IMA) grafts remain patent. Chronic total occlusions (CTO) in patients after CABG suggest more advanced state of atherosclerosis. Although precise mechanism of atherosclerosis in these patients is unknown, several clinical studies reported that atherosclerosis progression occurs more rapidly in grafted than in non-grafted arteries.

These data support the fact that IMA has favorable metabolic effect not only in the bypass, but also in the bypassed artery, which, according to the authors, is defined by NO products.

The frequency of occlusion of initially stenotic arteries in the proximal or distal segment was about $22 \%$ after the application of IMA grafts and on average $48 \%$ after autovenous grafts. According to literature data, in multivariate analysis, bypass interventions are independently associated with higher hospital mortality and perioperative complications. Mortality rate was $2.6 \%$ if the artery recanalization was successful, $5.2 \%$ in case of a partial success and $8.2 \%$ in case of failure.

This paper presents the analysis of possible interventional approaches to recanalization of the coronary bed in patients after CABG, discusses actual experience and practical developments. Fifty-two patients underwent recanalization of chronic occlusions of the coronary arteries at different times after CABG with a total technical efficiency of $75 \%$. In 11 patients with CTO, repeated recanalization attempts were made with an efficiency of $54.5 \%$. The third attempt was effective in two patients. Thus, the secondary efficacy of interventions was about $88 \%$. An intravascular ultrasound (IVUS) was used in $3.8 \%$ of patients.

One patient died during intervention as a result of collateral rupture at an attempt to perform retrograde approach when a "dry tamponade" occurred that led to cardiogenic shock.

Thus, CTO after CABG have unfavorable characteristics for recanalization and are more technically demanding than occlusion of arteries without prior coronary artery bypass grafting. Retrograde access is much more common here, and the effectiveness of intervention is significantly lower than that in primary patients. Repeated attempts to recapitalize the artery in case of prior unsuccessful attempt may significantly improve the results and were effective in half of the cases.

Keywords: coronary atherosclerosis, coronary artery bypass grafting, chronic coronary occlusion, coronary artery stenting. 


\title{
Особливості інтервенційних втручань при хронічних коронарних оклюзіях у хворих з ішемічною хворобою серця після аортокоронарного шунтування. Стан питання і власний досвід
}

\author{
Фуркало С. М. \\ ДУ «Національний інститут хірургії та трансплантології ім. О. О. Шалімова НАМН України», м. Київ, Україна
}

Резюме. Протягом 10 років після аортокоронарного шунтування (АКШ) $60 \%$ венозних шунтів і $90 \%$ трансплантатів внутрішньої грудної артерії (ВГА) залишаються функціонуючими.

Частота прогресування проксимальних стенозів шунтованих артерій до повних оклюзій становить $22 \%$ при використанні ВГА як артеріального анастомозу і $48 \%$ у середньому після застосування аутовенозних трансплантатів. Відповідно до літературних джерел, при багатофакторному аналізі хворі, які перенесли АКШ та піддаються подальшій коронарній ангіопластиці, мають вищий ризик втручання щодо смертності та післяопераційних ускладнень. Якщо реканалізація артерії пройшла успішно, смертність становила 2,6 \%, у разі часткового успіху $5,2 \%$, а в разі невдачі, летальність досягала $8,2 \%$.

При втручаннях у хворих після АКШ кращим є реканалізація оклюзій нативних коронарних артерій, ніж аортокоронарних трансплантатів.

У цій роботі представлений аналіз можливих інтервенційних підходів до реканалізації коронарного русла у хворих після АКШ, обговорено власний досвід і практичні напрацювання. Реканалізації хронічних оклюзій коронарних артерій в різний термін після АКШ із загальною технічною ефективністю 75 \% зазнали 52 хворих.

Повторну спробу реканалізації ХКО з ефективністю 54,5 \% перенесли 11 пацієнтів. Третя спроба була ефективна ще у двох хворих. Таким чином, вторинна ефективність інтервенційних втручань становила близько $88 \%$. Внутрішньосудинне ультразвукове дослідження застосовано у 3,8 \% пацієнтів. Один хворий помер під час втручання внаслідок розриву колатералі при спробі ретроградної реканалізації судини та виникнення «сухої тампонади», що призвело до кардіогенного шоку.

Отже, хронічні оклюзії коронарних артерій після АКШ мають несприятливі характеристики для реканалізації і більш технічно вимогливі, ніж оклюзії артерій без попереднього коронарного шунтування. Ретроградний доступ тут застосовується значно частіше, а ефективність втручання помітно нижча, ніж у первинних пацієнтів. Повторні спроби реканалізації артерії при раніше безуспішній спробі дозволяють істотно поліпшити результати і були ефективні в половині випадків.

Ключові слова: атеросклероз коронарних артерій, аортокоронарне шунтування, хронічні коронарні оклюзії, стентування коронарних артерій.

Стаття надійшла в редакцію 01.04.2019 р. 